\title{
Research on the Local Culture and Corresponding Influences on English Linguistics from the Etymology Perspective
}

\author{
Xiaomei Wen \\ Hubei University of Science and Technology, \\ Xianning, Hubei ,437100 China
}

\begin{abstract}
In this paper, we conduct research on the local culture and corresponding influences on the English linguistics from the etymology perspective. In the form of linguistics, language is a form of system, the research is in the form of the combination of form and meaning, language learning is rules and skills to master. In systemic functional linguistics, language is a system the study is in the context of significance. Language learning, therefore, the use of language, masters the language knowledge and skills in practice and the social culture. From a social point of view of language learning, language learning is no longer the pure knowledge and skills to master the cognitive process of memory, but a process of social interaction between individuals. Our research starts form the in-depth analysis of the etymology to propose novel perspective that is innovative and meaningful.
\end{abstract}

Keywords- Local Culture, English Linguistics, Etymology Perspective, Basic Influences.

\section{Introduction}

The development of linguistics plays an immeasurable role in English teaching. From the traditional grammar, communicative grammar, basic generative grammar and syntax structure, linguistics has undergone several big changes, development to today have become a comprehensive interdisciplinary research field as the development of linguistics not only expands the research category of linguistics, but also greatly promotes the foreign language teaching and made unprecedented progress.

Language features and language skills are two different concept of language, language function is intrinsic to the language, and language skills are gradually formed through long-term practice. With the development of linguistics, linguist large changes have taken place with the notions of language. They believed that language is a kind of speech act that has three dimensional function of language and it includes the following three aspects. (1) Language uses form symbols to express all interesting, has the function of expression, the emphasis on language contact in the real world. (2) Language is a purposeful behavior has a social function. It contains a certain emotion, it highlights the language is a social and cultural background between the person and the communication tool. Understand the three dimensions of language teachers, in the teaching process is not isolated to teach language knowledge, don't ignore or lacerate language meaning and function, and will try to put the language form and the language meaning and language function of three organically. (3) Language is a kind of conventional sound symbols or written symbols, with functions of description. People according to the language system rules in the form of sound or writing, presentation on factual information and this emphasis on language is a system of the primary rules [1-3].

The expression form and meaning of the word sometimes have some internal connection between motivations of words. Words to can be divided into phonetic motivation, morphological motivation, we according to the origin, etymological motivation is one of the main characteristics and evolution of language development, to a certain extent, reflects the language of the culture and history. In English 
language teaching, especially in vocabulary teaching, properly into the etymology teaching, therefore, can deepen the understanding of the penetration and language internal culture [4].

Teaching English language to research results should be applied in the practice, as should not only consider the learners to improve their language, and to increase the student information input to make it of the vocabulary learning that extend beyond form, sound and meaning of the cultural background. Etymology teaching has significant meaning to cultivate students' confidence and interest. Learners in the process of learning the vocabulary, if we can learn and expressions with the etymology of the core information, on the one hand to strengthen initiative of classroom teaching, knowledge and interest, on the other hand can change traditional teaching vocabulary teaching of language and culture of an organic whole so as to improve the teaching quality. Correspondingly, we demonstrate developmental path of the English linguistics in the following figure one.

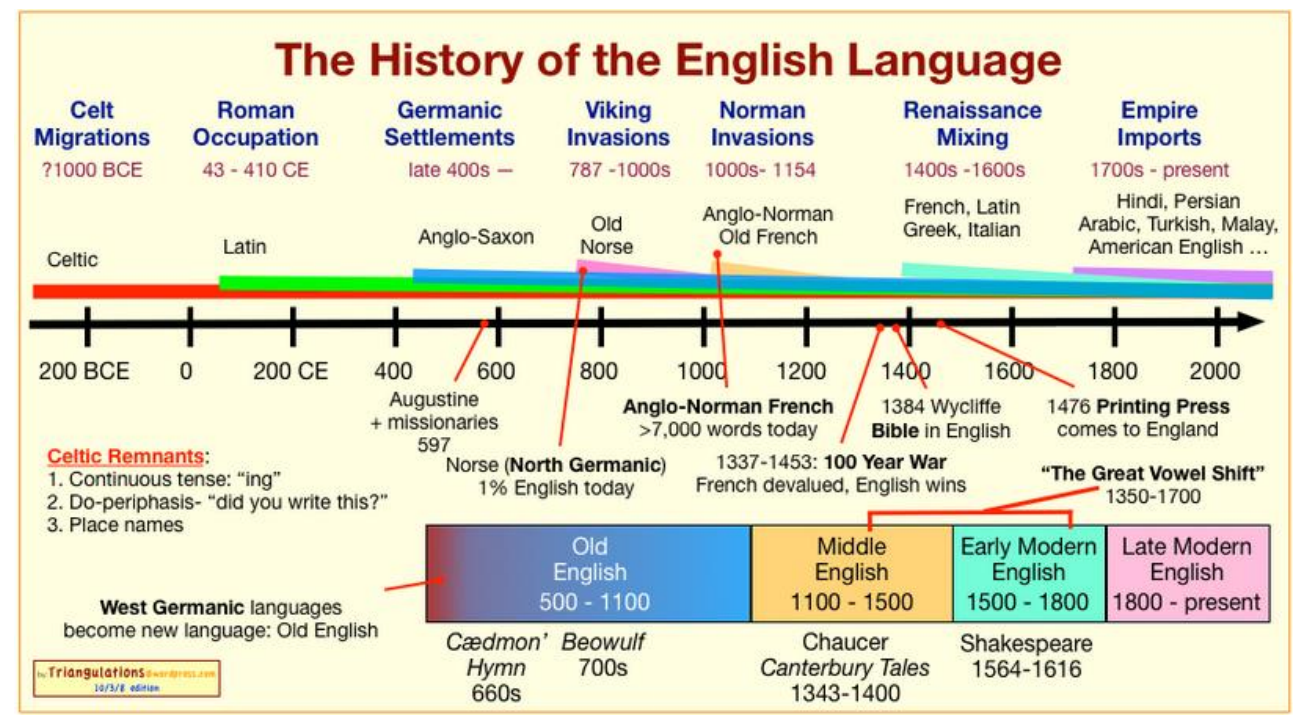

Figure 1. The Developmental Path of the English Linguistics

In this paper, we conduct research on the local culture and corresponding influences on the English linguistics from the etymology perspective. As a part of culture, language is the carrier of culture, and culture and language background, influence and restricts the language. Language and the culture are inseparable, complement each other. If we want to learn a foreign language, we must understand the language of culture and in some components of a language, closest relationship between vocabulary and culture. Etymological motivation is closely related to the nation's history and culture while the etymology of English to contain the rich and complicated history and culture, with strong ethnic and cultural personality. Foreign language learners should fully consider the etymological reasons and because of the unique history and culture to respect the vocabulary of ethnic and cultural personality. In the later sub-sections, we will propose our perspectives on the issues.

\section{The Proposed Methodology}

The British and American Culture. Language is the basic carrier of culture. Cultural learning is an important premise to learn and understand a language. English learners understanding of British and American and the western culture degree decided his communicative competence. Cross-cultural communication refers to native 
speakers with the native language of communication, also refers to the different cultural background, the communication between people of the different languages. Due to different cultural backgrounds, different ways of the communication, in the conversation, if we don't understand each other's cultural differences, with their inherent thinking to understand each other's words, caused a lot of barriers to communication and even misleading. Increase in the number of the exchanges with China's opening to the outside world, and the world, after graduating from higher vocational students are inevitably have to step into society, cross-cultural communication in foreign exchange has strong ability of communication also decided students' employment and development.

The functionality of the culture could be generally summarized as the follows. (1) Language is not only a tool of human communication, but also people with cultural fusion of medium. Language is the carrier of culture, they depend on each other; Language reflects the culture and spread culture. The spread of English as a lingua franca in the world at the same time, also at the same time, the British and American culture, western ideology and values spread in world, so-called linguistic imperialism. (2) In addition to the communication function, in the process of cross-cultural communication, a kind of language but also a symbol of a person's national identity. National identity is directly linked with the existence of the national language. A country's language is not just the government's work or the education language is also the person as a status symbol of its citizens. To learn the language of the world that is an important concept of "identity". (3) To communicate. Lingua franca makes language status of English in the process of cross-cultural communication become the choice of people from different cultural background together, the purpose is to keep the understandability of each other. So, the English can be regarded as a carrier of cultural diversity [5-6].

Language can be a carrier of national culture, carry forward and inheriting their thoughts and the culture. British and American literature review type belongs to a branch of English literature, British and American literature language needs for processing, sorting, itself will have specific meanings, which have certain representativeness. Cultural inheritance functions successfully in the UK to show English language use. In British literary criticism, as a result of the British literary critic of the English language have a sincere respect to make the best use of the English language. American English is derived from British English and there is no change in the core. The United States is a new country, his native culture, political system and the state is new while full of innovation and rebellious.

The English Linguistics Development. Linguistics is an important theoretical subject, aims to study the connection between the language phenomenon and language phenomenon and law to make people understand the nature of language, structure and rules, thereby utilizing the knowledge of the linguistics to explain various language activities. 


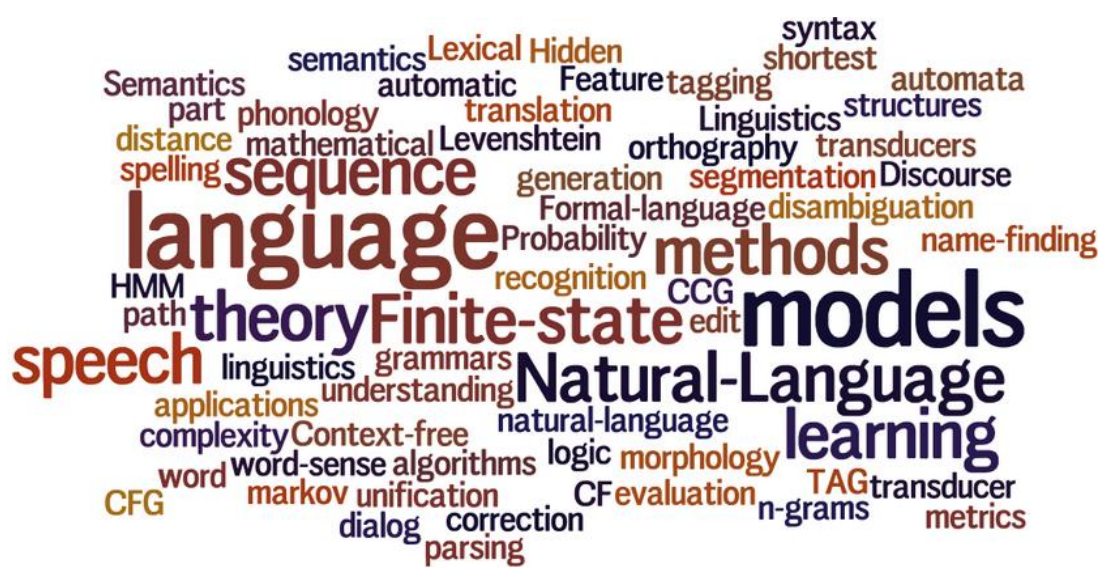

Figure 2. The Keywords of the English Linguistics

As shown above, we demonstrate the keywords of the English linguistics. Frame theory from the perspective of cognition, the framework as an embodiment of human cognitive structure, the study of human how to through the meaning of words, activation and the ingredients of the words is closely related. People in order to understand the meaning of the language, the first to search related concepts in the brain structure, the concept of structure for the word in the language and words and using of the background and motivation. The concept of structure is the semantic framework as the framework is composed of interrelated concepts, to understand any of this system concept, we must understand the whole concept system, introduce any a concept will activate all other concepts.

With these concerns, we shoud integrate the linguistics into the English education form the listed aspects. (1) On the basis of the theory of the comparative. Linguistic theories to the real language phenomenon analysis, explain the cause and effect, achieve the result of understanding to some extent. A careful analysis of these theoriescan find their inner link; Comparing these theories can get a more profound understanding. To reinforce the understanding of basic stage of the theory, corresponding to the further theoretical research. (2) Combined with theory. In order to make the class vivid, and fully mobilize the enthusiasm of the students, weu can also start with some language phenomena, then let students make judgments according to these phenomena, analysis, concept the formation, comparison between classmates conclusion, finally, the summary of the conclusions and contrasting linguistics theory, certain advantages make up the shortfall. For example we in pragmatics chapter comes into contact with the cooperative principles of conversation, namely in the conversation should pay their own efforts to cooperation enables the conversation to go smoothly to achieve the desired effect. (3) Requires students to pay attention to the language phenomenon around to make analysis and make the abstract theory linked to specific language practice. Linguistics theory is a basic theory of language knowledge, it is derived from the language practice, but also must use it to guide language practice. Therefore, in the foreign language learning, language theory is necessary, it can help us to master a language characteristics, and can guide us consciously learning language. (4) Guide students to active thinking. To make theory and basic course of contact need to pay attention to positive guidance to the student, the teacher let the students people think take the initiative to find language phenomenon, with understanding of linguistics, thus searchs from psychological set a positive attitude [7].

The Etymology and Culture. Etymology is to explore the source of the word and the 
evolution of a discipline and is a branch of linguistics. To explore the relationship between the pronunciation and meanings of a word is certain to be referred to the source of word and the word formation according to the problems such as management, in a sense it is also a fundamental theoretical problem in modern linguistics. Pair of source and study the relationship between the pronunciation and meanings of both in China and in the west to carry out early, and formed their own theory and research method of the system. Western etymology and Chinese etymology in basic theory and research methods is there are a lot of in common, but because of the different academic origin and starting point to each other, and so on the methodology and there are many differences as well as the specific research methods.

Chinese etymology can not only draw lessons from the research method of historical comparative linguistics and western etymology should also absorb the western other linguistic theories, such as the theory introduced study of etymological meaning analysis on metaphor theory of cognitive linguistics on the formation mechanism of the etymological meaning interpretation, etc. So we can put Chinese etymology in larger context, both absorb achievements of western linguistics, and rich achievements of general linguistics theory in its own right. In the traditional vocabulary teaching, many English instructors believe that let the students master the pronunciation of a word meaning, spelling and one or two major Chinese even mastered a word, let them by rote, one-sided pursuit of the vocabulary enlargement, and not to guide the student to find a quick way to memorize English words. Learning etymology and word formation, on the one hand, we can expand your vocabulary as soon as possible, in the process of reading don't have to look up the dictionary or less you can judge some don't know the meaning of the word and part of speech that can learn native, on the other hand, the potential of language knowledge, culture, history of the English-speaking world and all aspects of social life, so as to stimulate the enthusiasm of the learning procedures [8].

Because only through the comparison can know more clearly commonness and individuality of the object being compared, if pure closed, a single study, some of the commonness and individuality is not easy to be found. System also has universality, because related things will always be a common characteristic, if according to one common characteristic, put those related elements together to form a system, you can tease out in this system the internal relationship between the elements. It is the basis of semantic field theory of link, that through together we set up a specific semantic field. In paronym study, we can put the sound nearly word of link together, and then by comparing the probe word family internal contact characteristics, pronunciation and the meaning of each word formation and the extension of deep structure, etc.

\section{Conclusion}

In this paper, we conduct research on the local culture and corresponding influences on the English linguistics from the etymology perspective. For college English major students, learning a foreign language and children's acquisition of mother tongue is different, especially language environment, imitation and partly due to the interference of bilingual phenomena. Therefore, only by mastering the skills of listening, speaking, reading and writing translation of the various aspects is limited, it's just learning English as a tool that it is not enough for the students. They should learn to certain theoretical methods are used to explain various language phenomenon, to deepen the understanding of language, strengthen the ability to consciously to learn a language. Only have solid basic theoretical knowledge of linguistics to expect students to have a more profound attainment in the language learning, some 
development in linguistics. In the future research, we will review more state-of-the-art perspectives on the related topics to enhance our contemporary methodology.

\section{References}

[1] Xu, Diana. "Reviewer Acknowledgements for International Journal of English Linguistics, Vol. 5, No. 4." International Journal of English Linguistics 5.4 (2015): 154.

[2] Boulton, Alex. "Learning and using English with corpora: Insights from a meta-analysis." English Linguistics and Corpus. 2015.

[3] Moreno, Ana I. "The communication problems of Spanish researchers to get research articles published in Applied Linguistics English-medium journals: proposal and analysis." (2012).

[4] Walicek, Don E. "Book Review: Linguistics in a Colonial World: A Story of Language, Meaning, and Power." Journal of English Linguistics 40.2 (2012): 216-219.
[5] Tagliamonte, Sali A., and R. Harald Baayen. "Models, forests and trees of York English: Was/were variation as a case study for statistical practice." (2012).

[6] Qin, Xiaohui. "A Comparative Study of Activity Preferences of Learners and Teachers in College English Teaching and Its Implications for Curriculum Design." International Journal of English Linguistics 2.6 (2012): p40.

[7] Pan, Yi-chun. "Effects of Multi-Faceted Lexical Instruction on the TOEIC Listening Performance of Taiwanese EFL College Students." International Journal of English Linguistics 2.6 (2012): p71.

[8] Arabi, Hamid Abdalla, and Nauman Al Amin El Sayed. "Patterns of Textual Coherence in Students' Written Discourse: A Study of Sudanese English Majors." International Journal of English Linguistics 5.1 (2015): p91. 